\title{
Os Sindicatos Brasileiros em face das Inovações Tecnológicas e Organizacionais*
}

\author{
Fernando Coutinho Cotanda
}

"Nós ficamos falando que o modelo toyotista japonês é ruim como se o modelo anterior fosse bom. Como nós queremos trabalhar, essa é uma discussão central para nós, para a Central, para o movimento sindical do mundo inteiro.

Se nós ficássemos desde o início só falando que a reestruturação é uma estratégia do capital para cooptar os trabalhadores, sem tentar interferir, nós íamos ficar falando sozinhos. [...] Se você ficar de fora, simplesmente já perdeu [...]" (Valter Sanchez, engenheiro, membro da Comissão de Fábrica da Mercedes-Benz de São Bernardo do Campo, em entrevista concedida em 2001).

este artigo, é examinada a relação entre sindicatos brasileiros fili-
ados à Central Única dos Trabalhadores $-\mathrm{CUT}^{1}$ e processos de inovação tecnológica e organizacional em curso nas empresas brasileiras desde os anos 1990. Os motivos que me conduziram a este estudo, que tem como foco principal a problemática da influência sindical sobre os processos de inovação, são diversos. Na origem está minha perplexidade em face da dificuldade encontrada pelos valores democráticos presentes em outras esferas da vida social - de se fazerem presentes nas empresas, notadamente no que concerne às decisões que envolvem

\footnotetext{
* Agradeço os comentários dos pareceristas anônimos da revista DADOS. Dedico este artigo a Luís Paulo Bresciani, Mario Sergio Salerno, Nilson Tadashi Oda, Glauco Arbix e Valter Sanchez.
}

DADOS - Revista de Ciências Sociais, Rio de Janeiro, Vol. 51, nº3, 2008, pp. 617 a 646. 
a produção. Outro motivo é a expectativa de que os sindicatos venham a ampliar e qualificar seu engajamento nesses temas tidos como de exclusiva competência gerencial e cuja importância para a vida social é inequívoca.

Os excertos apresentados a seguir põem em destaque o lugar comumente ocupado pelo tema inovação tecnológica e organizacional na vida sindical:

Os conflitos e negociações entre capital-trabalho no século XX foram caracterizados pela discussão de salários e condições gerais de trabalho (horário, segurança, benefícios, etc.) e não pelos temas de organização do trabalho e gestão [...] (Salerno, 1999:202).

Os sindicatos (com raras exceções), mantidos na porta das fábricas, não criam expertise para negociar em pé de igualdade com as empresas a renovação dos processos produtivos, com o que elas puderam fazê-lo de forma quase sempre unilateral (Cardoso, 1999:167; ênfases do autor).

Também me conduziu a este estudo a discordância com posturas recorrentes no movimento sindical (mas não exclusivamente) que protelam a atuação sindical sobre os assuntos da produção em nome de projetos de transformação social mais amplos, supondo que aquela dimensão da atuação sindical seria factível somente a partir da superação do Estado capitalista. Ao revés, acredito que os projetos de transformação social ficam fortemente comprometidos se os trabalhadores não afirmam no presente sua utopia para o trabalho.

A identificação dos obstáculos que se opõem à proatividade sindical nos assuntos relativos ao processo de trabalho constitui um campo de estudo - para o qual este artigo pretende contribuir - que ainda carece de pesquisas empíricas e de aprimoramento analítico.

\section{O PROBLEMA DE PESQUISA}

Desde meados dos anos 1980, a CUT tem formulado e atuado sobre as inovações tecnológicas e organizacionais avaliando as conseqüências da reestruturação produtiva para as relações de trabalho; definindo, em seus congressos, posicionamentos (formais) sobre os processos de inovação; afirmando a pertinência de atuar sobre os assuntos da produção tidos como prerrogativa essencialmente gerencial; produzindo experiências em diferentes frentes - micro e mesorregulatórias, insti- 
tucionais e legais - que, direta ou indiretamente, ensejam possibilidades de influência sobre os processos de inovação.

O principal argumento que pretendo demonstrar nesta investigação é que a CUT e as entidades a ela filiadas, apesar de afirmarem majoritária e formalmente a pertinência e o objetivo de influir sobre os processos de inovação ${ }^{2}$ e de procurar fazê-lo em diferentes níveis e dimensões, obtiveram limitado êxito nesse sentido. Na produção desse resultado, estiveram implicados fatores sobre os quais a governabilidade do sindicalismo "cutista" é reduzida, tais como: sistema de relações de trabalho; decisões políticas de cunho macroeconômico; cultura empresarial refratária à negociação dos processos de inovação; assimetria de poder entre capital e trabalho; entre outros. Entretanto, conforme busco enfatizar e demonstrar, o reduzido êxito do sindicalismo cutista em influenciar os rumos das inovações esteve associado também a suas próprias limitações: as estruturas internas dos sindicatos pouco adaptadas e capacitadas para formular mudanças tecno-organizacionais e para interagir com elas; o afastamento dos sindicatos dos locais de trabalho; os limitados vínculos sociais; entre outros constrangimentos que, a rigor, estão mais próximos de sua governabilidade.

Antes de discorrer sobre a metodologia empregada na pesquisa, faz-se necessário esclarecer que, embora todas as entidades sindicais examinadas sejam filiadas a uma central sindical, não se verifica homogeneidade na forma de conceber e tratar os processos inovativos no trabalho. Ao contrário, conforme será visto, estamos diante de um sujeito social heterogêneo no que concerne aos recursos materiais disponíveis e às estratégias de ação política. Fatores como história da entidade, tamanho de sua base, importância econômica do setor ao qual pertence, vínculos sociais, capacidade de proposição e de mobilização de recursos políticos, concepções sobre o papel dos sindicatos, entre outras variáveis, concorrem para a determinação de diferenças substantivas na forma e no conteúdo das ações das diferentes entidades.

A pesquisa realizada e o exame da literatura permitiram a identificação de quatro posturas sindicais no que concerne ao envolvimento sindical em face dos processos de inovação tecnológica e organizacional.

Acredito que uma das posturas mais recorrentes no sindicalismo brasileiro em relação a inovação pode ser chamada de silenciosa. Remete a uma situação na qual o tema da inovação no trabalho está formalmente presente nas negociações coletivas; porém, paradoxalmente, ausente 
de todas as demais atividades do sindicato. A incorporação de cláusulas sobre os processos inovativos nas negociações se dá por força do "contágio" com outras entidades. As cláusulas são literalmente copiadas e passam de entidade a entidade sem que seja promovida nenhuma mudança interna nos sindicatos a fim de dar suporte ao tema do processo de trabalho e da inovação. Pode-se afirmar que o envolvimento sindical nos assuntos da produção com vistas à negociação não é objeto de problematização por parte da entidade, restando apenas o silêncio. Uma parcela dos sindicatos examinados neste artigo se enquadra nesse tipo de postura.

Outro conjunto de entidades sindicais assume uma postura que denomino refratária ao envolvimento sindical nos assuntos da produção. A intenção de negociar os processos inovativos é interpretada como uma ação legitimadora dos interesses de valorização do capital. Essas entidades são formalmente contrárias ao envolvimento sindical nesses assuntos. São minoritárias no interior da CUT e não estão entre as entidades examinadas neste artigo.

Foram identificadas ainda entidades que assumem uma postura que chamo de sensibilizada. São sindicatos que, ao contrário do "silêncio" e da atitude "refratária", manifestam formalmente a concordância com a necessidade do envolvimento sindical nos assuntos da produção com vistas à negociação. Contudo, essa "sensibilidade" para com o tema se dá exclusivamente no plano discursivo, sem que seja promovida nenhuma prática efetiva para levar a termo suas manifestações discursivas. A diferença em relação à postura "silenciosa" reside no fato de afirmarem, ainda que apenas discursivamente, a importância de os sindicatos atuarem sobre os processos inovativos no trabalho. A maior parte das entidades examinadas no presente artigo são portadoras de uma postura "sensibilizada".

Somente um número diminuto de sindicatos no Brasil apresenta uma postura que aqui denomino afirmativa com respeito à necessidade e à pertinência de influir nos assuntos da produção. Trata-se de entidades que procuram desenvolver capacitação e recursos políticos que viabilizem as estratégias de influência sindical nos temas relativos às inovações tecnológicas e organizacionais. São entidades que procuram identificar e superar os obstáculos que estão mais próximos de sua governabilidade promovendo mudanças internas nas entidades, dotando- 
as de meios técnicos e organizacionais adequados à perspectiva de influência sindical nos assuntos da produção.

\section{METODOLOGIA}

No presente artigo, são consideradas âmbito empírico de pesquisa as entidades sindicais majoritariamente filiadas à CUT. É analisado o teor das cláusulas de acordos e / ou convenções coletivas celebrados no período de 1990 a 2005, entre sindicatos e empresas, envolvendo o tema da inovação. Em outro momento da pesquisa, busco compreender, por meio de entrevistas com dirigentes sindicais, o que ocorreu após a contratação das cláusulas, ou seja, se a influência sindical sobre os processos de inovação foi efetiva ou aparente. Em decorrência da pesquisa, sugiro a existência de um conjunto de obstáculos à disposição sindical de influir sobre os processos de inovação. É enfatizada a análise dos obstáculos (endógenos) mais próximos da governabilidade sindical.

Tendo em vista a inexistência de um banco de dados que acolha e consolide o universo das negociações coletivas dos sindicatos brasileiros, este estudo se baseia nas seguintes fontes para identificar e analisar as cláusulas de acordos e/ou convenções coletivas: no Sistema de Acompanhamento de Contratações Coletivas/Departamento Intersindical de Estatística e Estudos Socioeconômicos - SACC/Dieese; na literatura que versa sobre o tema; e na pesquisa desenvolvida por mim com as entidades sindicais.

O sistema de acompanhamento de cláusulas do Dieese é integrado, majoritariamente, por convenções coletivas. Desde 1993, quando foi implementado o sistema, até 2002, o Dieese coletou anualmente 94 documentos (acordos e convenções coletivas) que abrangem cerca de trinta categorias profissionais em quatorze unidades da Federação. A partir de 2003, a base de dados do sistema foi ampliada para 225 contratos coletivos por ano, abrangendo cinqüenta categorias profissionais e dezesseis unidades da Federação:

[...] este é um levantamento de caráter qualitativo, dado que as categorias que compõem o painel foram intencionalmente escolhidas. Assim, por não se tratar de uma amostra estatística, seus resultados não são passíveis de generalização, embora as informações permitam identificar a situação das negociações coletivas das categorias profissionais que historicamente se colocam como referência no panorama sindical brasileiro (Dieese, 1999:10; ênfase do autor). 
O Dieese procura orientar a escolha das entidades levando em consideração a diversidade e a representatividade política dos sindicatos nas diferentes regiões do Brasil. As cláusulas examinadas tiveram origem em mais de cinqüenta entidades sindicais e federações de trabalhadores. Possuem uma significativa abrangência e diversidade geográfica: Bahia, São Paulo, Rio de Janeiro, Distrito Federal, Rio Grande do Sul, Goiás, Minas Gerais, Paraná, Rio Grande do Norte, Pernambuco, Ceará. É extenso também o número de categorias profissionais envolvidas nas negociações: metalúrgicos, petroquímicos, jornalistas, telefônicos, construção civil, mobiliário, vestuário, farmacêuticos, radiodifusão e televisão, aeroviários, gráficos, rodoviários, entre outras. Do total de cláusulas acordadas examinadas, mais da metade pertence a categorias do setor industrial, seguidas pelas categorias dos setores serviços e comércio.

Após a análise das cláusulas que incidiam sobre os processos de inovação, teve início uma série de entrevistas com os dirigentes sindicais em 35 entidades sindicais promotoras das negociações para apurar o que ocorreu após a contratação das cláusulas ${ }^{3}$.

Uma das experiências de negociação mais importante realizada no Brasil envolvendo inovações, nos anos 1990, foi levada a termo pelo Sindicato dos Metalúrgicos do ABC, pela Comissão de Fábrica da Mercedes-Benz e pela empresa Mercedes-Benz de São Bernardo do Campo. Essa experiência, por sua singular riqueza, impõe a necessidade de um espaço mais amplo - para descrição e análise - do que o possível nos limites deste artigo, ficando assim ausente do presente estudo ${ }^{4}$.

\section{AS ENTIDADES SINDICAIS CONTRATANDO PROCESSOS DE INOVAÇÃO: ACORDOS E CONVENÇÕES COLETIVAS}

\section{Características das Cláusulas Contratadas: Limites e Oportunidades}

O exame das cláusulas negociadas, diretamente relacionadas aos processos de inovação, permitiu identificar que seu conteúdo versa basicamente sobre cinco pontos: treinamento; reaproveitamento; comunicação referente a processos de inovação; comissões paritárias; e inovação/emprego.

A seguir, à guisa de ilustração, é apresentada uma relação de excertos de algumas cláusulas contratadas ordenadas por conteúdo ${ }^{5}$ : 
Treinamento em face da introdução de inovações

- "[...] as empresas promoverão, quando necessário, treinamento para os trabalhadores."

- “[...] as empresas promoverão, quando necessário e ao seu critério, treinamento para os empregados."

- "[...] recomenda-se treinamento para aprendizagem na eventual ocupação de novas funções."

- "As empresas propiciarão treinamento em outro cargo [...] desde que exista vaga em outro setor e que o trabalhador esteja em condições de assumi-lo."

Reaproveitamento em face da introdução de inovações

- "[...] os trabalhadores [...] contarão com o empenho do empregador para o seu aproveitamento em outra função."

- "[...] a empresa se compromete a reaproveitar, sempre que possível, trabalhadores atingidos [...]."

- "[...] estudar remanejamento interno mediante requalificação profissional."

- "[...] reaproveitar, sempre que possível, em outros setores os trabalhadores atingidos [...]."

Comunicação ao sindicato e/ou aos trabalhadores sobre eventuais processos de inovação

- “[...] a empresa deverá comunicar o sindicato com antecedência de 6 meses em face da implantação de novos processos."

- "[...] manter os empregados informados."

- "As empresas [...] comprometem-se a manter os trabalhadores do setor informados em relação aos projetos em andamento [...] desde que não seja prejudicial aos interesses das empresas perante a concorrência."

- "A empresa assegurará ao sindicato o conhecimento da implantação e do tipo de automação que se pretende instalar e o número de atingidos pelo respectivo projeto [...]." 
Manutenção do emprego em face da introdução de inovações

- "[...] estabilidade de dois meses para empregados não aproveitados no setor modificado."

Comissão paritária para tratar de assuntos relativos a inovação

- "[...] comissão paritária intersindical."

- “[...] criar comissão paritária."

A leitura dos excertos permite-nos verificar que se trata de cláusulas que apresentam redações cujas formulações são predominantemente genéricas, contingentes e defensivas. A generalidade das cláusulas pode ser creditada ao fato de que a maioria delas tem, nas convenções coletivas, seu instrumento jurídico. As negociações realizadas entre um sindicato e diversas empresas, diferentemente do acordo coletivo, podem estabelecer algum impedimento a um maior detalhamento das cláusulas. Existe, no entanto, outra face dessa generalidade, que é a dificuldade, sentida pelas entidades, de precisar sua demanda em relação aos temas da produção. A título de ilustração, cabe referir a fala de um dirigente do Sindicato dos Bancários de Porto Alegre. No início dos anos 1990, esse sindicato contratou uma cláusula que lhe garantia direito de informação por ocasião de inovações tecnológicas: “[...] informação ao sindicato dos projetos de informática que alterem relações de trabalho". Perguntado sobre o uso feito pelo sindicato durante a vigência dessa cláusula, o dirigente respondeu:

[...] não havia uma regulamentação precisa deste acordo $e$ a gente também não sabia o que pedir [...] são acordos que não funcionam [...] mais recentemente, nós participamos da comissão paritária nacional que discute esta cláusula e nós temos problemas, porque a gente até obtém as informações, mas não dá tempo de atuar, quando vê, as mudanças foram feitas (dirigente do Sindicato dos Bancários de Porto Alegre e Região; ênfase do autor).

A generalidade das cláusulas, portanto, não é expressão exclusiva da natureza do instrumento jurídico, a convenção coletiva, mas também das dificuldades das entidades sindicais de afirmar o que exatamente estão buscando.

As entrevistas realizadas com as entidades sindicais possibilitaram perceber que, embora o número de cláusulas negociadas nos anos 1990 seja significativo, nem todas foram originadas na entidade. Os sindica- 
tos com menor força copiaram ou adaptaram cláusulas de sindicatos mais fortes. Isso pode indicar que o teor da cláusula não é expressão de uma dinâmica de ação e de reflexão interna do sindicato.

Todas essas limitações estão associadas à precária presença dos sindicatos nos locais de trabalho, à falta de conhecimento sobre o tema, além de outros obstáculos específicos que serão analisados mais detalhadamente adiante.

Outra característica das cláusulas examinadas é seu conteúdo predominantemente contingente. A redação de um grande número de cláusulas, conforme se observa nos excertos anteriores, possui condicionantes que tornam sua aplicação eventual e incerta: "recomenda-se treinamento"; "treinamento em outro cargo [...] desde que exista vaga"; "[...] reaproveitar, sempre que possível [...]"; "empenho do empregador para o seu aproveitamento em outra função"; acesso a informações sobre processos de inovação "desde que estas informações não representem quebra de sigilo nem seja prejudicial aos interesses das empresas [...]".

Finalmente, as cláusulas acordadas apresentam, em sua maioria, características predominantemente defensivas e corretivas, ou seja, buscam intervir depois da implementação das mudanças nas empresas, procurando corrigir as conseqüências negativas para os trabalhadores.

Todavia, ainda que as cláusulas acordadas sejam preponderantemente defensivas, genéricas e contingentes, elas ensejam possibilidades significativas para a atuação sindical diante das transformações no mundo do trabalho. Entretanto, para se concretizarem, essas possibilidades necessitam de um qualificado investimento político e técnico por parte dos sindicatos.

\section{A Efetividade da Contratação das Cláusulas sobre os Processos de Inovação}

Quais foram os desdobramentos concretos das cláusulas sobre os processos inovativos negociadas? O que ocorreu depois que as negociações foram realizadas? Qual foi a interação dos sindicatos com os objetos contratados?

Preliminarmente, faz-se necessário considerar que, por meio de pesquisa realizada junto ao SACC/Dieese e a entidades sindicais, foram verificadas três ocorrências básicas com as cláusulas negociadas ao 
longo dos anos 1990: deixaram de ser renovadas; sofreram alterações de conteúdo em sua redação; ou permaneceram inalteradas.

Foi constatado que a maior parte das cláusulas vem sendo renovada a cada nova negociação e, na maioria dos casos, sem alterações na redação. Ocorre que a existência desses contratos não garante por si só sua aplicabilidade concreta. Eles dependem, entre outros fatores, da postura e da capacitação dos sujeitos sociais envolvidos. Nesse sentido, dois fatores principais atuam simultaneamente: a postura patronal predominantemente refratária ao envolvimento dos sindicatos nos assuntos da produção e as dificuldades endógenas das entidades sindicais no tratamento do tema.

A constatação mais significativa, resultante da investigação realizada com os dirigentes sindicais visando identificar o que havia ocorrido após a contratação das cláusulas, é que nenhuma das quase quarenta entidades que constaram da pesquisa teve êxito em tornar efetivo aquilo que foi contratado ${ }^{6}$. Os depoimentos revelaram que as negociações conformaram um tipo de influência sindical sobre as inovações denominado "aparente" por Bresciani (1994), ou seja, firmado em contrato, mas sem ocorrer de fato.

A postura predominantemente refratária das empresas ao envolvimento sindical nos assuntos da produção atua para que essas conseqüências sejam observadas. Entretanto, temos de considerar que esse resultado decorre também das insuficiências internas dos sindicatos em relação à temática da inovação, notadamente o limitado desenvolvimento de capacitação nesse âmbito.

Durante as entrevistas realizadas com os dirigentes sindicais daquelas entidades, foram encontradas diversas manifestações que atestam a existência dessas dificuldades:

Isso praticamente não foi utilizado por nós [referindo-se à cláusula relacionada ao direito à informação] [...] e a gente sabe que a questão de fundo aí é o afastamento do sindicato do mundo do trabalho (diretor do Sindicato dos Telefônicos de Recife).

Isto acontece porque a categoria não dá importância a estes temas, eles querem discutir questões econômicas [referindo-se à cláusula sobre treinamento e remanejamento interno que não se tornou realidade] (diretor do Sindicato dos Metalúrgicos de Porto Alegre). 
Nosso sindicato não tem perna para tocar estas questões de novas tecnologias (diretor do Sindicato dos Aeroviários do Rio Grande do Sul).

A gente tem esta cláusula, mas não usa; essa é uma cláusula nacional (diretor do Sindicato dos Jornalistas Profissionais do Ceará).

O sindicato não consegue fazer esta discussão direito (diretor do Sindicato dos Metalúrgicos do Rio de Janeiro).

O forte da reestruturação produtiva já passou, então, este é um tema que não mexe mais tanto (diretor do Sindicato dos Metalúrgicos de Curitiba).

Nós temos uma diretoria de tecnologia aqui, mas ela não funciona para esses pontos (diretor do Sindicato dos Telefônicos do Rio Grande do Sul).

Este é um problema [referindo-se à inovação tecnológica] muito maior que os sindicatos, a gente não pode mudar nada aqui (diretor do Sindicato dos Químicos de São Paulo).

Nós não conseguimos interferir nos cursos que a empresa faz porque nós não temos know-how [referindo-se ao acordo sobre treinamento em face da automação] (diretor do Sindicato dos Gráficos de São Paulo).

Vale referir também que encontrar diretores sindicais que soubessem fornecer informações sobre os desdobramentos dos acordos foi um dos problemas recorrentes durante o trabalho de campo, o que revela o lugar ocupado por esses acordos na hierarquia de preocupações sindicais. Muitos nem sequer conheciam a existência dos acordos. Não foi raro ouvir expressões como "[...] acho mais fácil você obter esta informação no [Departamento] Jurídico".

Uma vez identificado o conteúdo genérico, contingente e defensivo das cláusulas que versaram sobre os processos de inovação e a falta de efetividade das mesmas, parece-me oportuno um esforço de caráter analítico para compreender quais são os obstáculos enfrentados pelas entidades sindicais no caminho da influência sindical sobre o processo de trabalho.

\section{OS OBSTÁCULOS À INFLUÊNCIA SINDICAL SOBRE O PROCESSO DE TRABALHO}

Na elucidação do objeto proposto, é indispensável considerar preliminarmente que o reduzido êxito do sindicalismo cutista em influir sobre os rumos das inovações não deve ser creditado a um exclusivo e determinante fator explicativo. Ao revés, penso que diversos fatores se opu- 
seram àquele objetivo formalmente enunciado pela CUT. Para efeitos do presente artigo, os obstáculos foram divididos analiticamente em dois tipos: exógenos e endógenos. O que os diferencia é a maior ou a menor governabilidade que os sindicatos possuem sobre esses obstáculos.

O termo governabilidade é aqui empregado em sua acepção etimológica para destacar que as dificuldades sindicais em influir sobre os processos de inovação não dependem, exclusivamente, do maior ou do menor constrangimento que sofrem os sindicatos e as classes trabalhadoras. De um ponto de vista relacional, as decisões políticas adotadas pelas direções sindicais e sua prática efetiva também estão implicadas na maior ou na menor dificuldade de influir sobre os processos de inovação. Não se trata aqui de "aplainar" a assimetria de poder existente entre capital e trabalho, mas sim de posicionar, em relevo, os espaços políticos que podem ser ocupados ou ampliados pelos sindicatos. A criação de estruturas internas aos sindicatos capazes de apoiar estratégias de influência sindical sobre os processos de inovação ou a ampliação de seus vínculos sociais com atores relevantes para o tema em questão, por exemplo, estão mais próximas da governabilidade sindical. A ampliação da oferta de emprego ou o controle da inflação estão, no entanto, mais distantes de sua governabilidade. A expressão governabilidade nos será útil para enfatizar as margens de atuação sobre as quais os sindicatos podem e devem ampliar sua presença como sujeitos.

\section{Obstáculos Exógenos ao Caminho da Influência Sindical}

Conforme já mencionado, este texto enfatiza a análise dos obstáculos endógenos. Entretanto, considerando que os dois tipos de obstáculo estão mutuamente referidos e que essa distinção arbitrária foi feita com finalidade analítica, torna-se imperativo dedicar algumas páginas aos obstáculos exógenos que dificultam a influência sindical sobre os rumos das inovações no trabalho.

Os assuntos relativos à produção permanecem sendo majoritariamente considerados uma prerrogativa essencialmente privada que diz respeito exclusivamente à gerência e à empresa - independentemente da posição ocupada nas classes sociais. É amplamente aceito na sociedade, inclusive entre os trabalhadores, que a forma de dispor dos meios privados de produção para atingir um determinado objetivo é atribui- 
ção exclusiva das gerências. Desse modo, o limitado interesse dos sindicatos com respeito a esse tema também é tributário de um processo de reificação dos significados do trabalho.

O obstáculo anteriormente referido - inscrito na cultura - se manifesta igualmente no plano legal. A gestão do trabalho e da produção é, em geral, assegurada legalmente como uma prerrogativa eminentemente patronal - o poder unilateral de mando do empregador. Na legislação brasileira, notadamente na Consolidação das Leis do Trabalho - CLT, a definição dos "entes" jurídicos empregador e empregado confere explicitamente ao primeiro o poder de "dirigir" e, ao segundo, a situação de estar "sob a dependência" do primeiro.

O sistema institucionalizado de relações de trabalho, dependendo de seu arcabouço jurídico, pode restringir ou coibir a organização dos trabalhadores nos locais de trabalho, fator-chave, embora não exclusivo, no caminho da influência sindical sobre os assuntos da produção. A estrutura de negociação entre capital e trabalho, quanto mais pulverizada, apresenta maiores dificuldades de pôr em prática estratégias sindicais articuladas e coordenadas. A ausência de estruturas meso ou macrorregulatórias do conflito entre capital e trabalho limita à esfera da empresa a possibilidade da intervenção sindical nos assuntos relativos à inovação tecnológica.

As particularidades históricas das formações sociais podem reforçar e atuar na reprodução social do poder de mando unilateral nos assuntos da produção. O escravismo no Brasil, por exemplo, cuja presença se fez sentir em cerca de dois terços de nossa história, contribuiu sobremaneira para a difusão de uma cultura de desvalorização do trabalho e para uma tradição autoritária no tratamento das relações de trabalho. No âmbito da empresa, isso se expressa por meio de uma postura gerencial refratária à negociação dos processos de inovação.

As formações sociais em que há expressiva concentração de renda, rebaixamento salarial e instabilidade no emprego, como no caso brasileiro, induzem os sindicatos a concentrarem esforços na defesa dos salários, no direito ao trabalho e nos demais direitos sociais elementares. Embora não exista incompatibilidade entre ações sindicais no âmbito econômico e aquelas referidas ao processo de trabalho, é razoável ponderar que a deficiência nos indicadores socioeconômicos oferece maiores obstáculos à atuação sindical. 
A formação escolar e profissional deficiente é outro obstáculo. Quanto piores os indicadores sociais nesse campo, mais dificuldades são postas ao envolvimento dos trabalhadores na formulação de alternativas aos modelos de organização do trabalho e de inovação tecnológica.

Em alguns segmentos econômicos, os grandes investimentos e mudanças tecnológicas são realizados tendo por base estratégias corporativas. A negociação coletiva se desenvolve em um nível, e as decisões sobre as inovações em outro. Produz-se uma assimetria entre o nível mais importante das decisões nas empresas e aquele no qual os sindicatos negociam.

A natureza e a aplicação dos "pacotes" de inovação tecnológica e organizacional também são obstáculos, visto que, em geral, prevêem uma participação instrumental dos trabalhadores sem que sejam considerados processos de negociação envolvendo suas entidades representativas.

As experiências históricas, como o "compromisso fordista", que "trocou" o acesso à renda e à proteção social aos trabalhadores pelo silêncio sindical em torno do tema, também se constituem em um amplo obstáculo.

A experiência soviética, que poderia estabelecer contrapontos alternativos aos modos de organização do trabalho no capitalismo, não o fez ${ }^{7}$. Ao contrário, a ausência da democracia que caracterizou aquela experiência contribuiu negativamente para o desenvolvimento da crítica às formas assumidas pelo trabalho no capitalismo: criticar a organização do trabalho nas economias industriais capitalistas seria o mesmo, dada a relativa semelhança, que criticar a experiência soviética.

O rol de obstáculos enunciado demonstra que a efetiva influência sindical nos assuntos da produção não depende exclusivamente da disposição dos sindicatos para fazê-lo. Existem inúmeros constrangimentos a esse intento, conforme procurei mostrar.

Ainda que tenha referido a existência de um conjunto de obstáculos exógenos à influência sindical nos assuntos da produção, este artigo, como já mencionado, confere prioridade ao exame dos obstáculos endógenos ${ }^{8}$. 


\section{Obstáculos Endógenos ao Caminho da Influência Sindical ${ }^{9}$}

As entidades sindicais que julgam pertinente a busca da influência sobre os rumos da inovação no trabalho terão diante de si outro conjunto de obstáculos.

Os obstáculos endógenos estão relacionados à ausência ou ao limitado desenvolvimento de capacitação por parte da entidade sindical para formular, propor, monitorar, negociar e mobilizar trabalhadores, sobretudo em relação aos processos de inovação nos diferentes âmbitos em que se manifestam as variáveis decisivas da produção: na empresa, nas instâncias legais, institucionais, meso e macrorregulatórias.

A pesquisa realizada possibilitou identificar quatorze obstáculos que, em maior ou menor grau, estiveram presentes nas entidades sindicais examinadas. A fim de tornar mais fácil a compreensão desses obstáculos, eles serão mostrados sob a forma de atributos sindicais que, estando ausentes ou parcialmente presentes, se tornam obstáculos.

Evidentemente que, ao referir os atributos, minha intenção neste artigo não foi propor um conhecimento normativo, uma "receita" a ser aplicada pelos sindicatos, tampouco imagino ter esgotado os caminhos pelos quais essas entidades poderiam capacitar-se para atuar de forma mais eficiente nos assuntos da produção. Trata-se de um esforço de análise, fruto de pesquisa empírica, para melhor compreender e demonstrar os constrangimentos que se interpõem entre os sindicatos e o caminho da influência sobre o processo de trabalho.

A ausência ou o parcial desenvolvimento dos atributos por parte dos sindicatos se traduzem em obstáculos à proatividade sindical nos assuntos da produção e, por extensão, ao cumprimento dos objetivos majoritariamente propugnados pela CUT de influir sobre os processos de inovação. Foram identificados, portanto, na pesquisa realizada, os obstáculos apresentados a seguir sob a forma de atributos:

\section{1) Político (processo de trabalho)}

Capacidade de reconhecer o(s) significado(s) político(s) do processo de trabalho incorporando esse tema às atribuições de natureza sindical. Assumir a prerrogativa de responder, em diferentes contextos, o que o trabalho significa e que trabalho se quer. 
Supõe a afirmação do processo de trabalho como um campo de conflito sobre o qual a entidade sindical deve atuar. Significa, portanto, a ruptura com concepções segundo as quais os assuntos relativos à gestão e à tecnologia na produção são uma prerrogativa exclusivamente empresarial ou que o envolvimento sindical com processos de negociação do processo de trabalho representa "gerir ou cooperar com o capitalismo". Na ausência de organização, pressão e propostas sindicais, as empresas seguem empunhando a bandeira da mudança do trabalho e transformando-o unilateralmente. A determinação política de atuar sobre o processo de trabalho deve estar substantivada na capacitação e na busca permanente de respostas: como pensar a organização do trabalho em bases diferentes? O que colocar no lugar daquilo que é criticado?

2) Constituição e/ou fortalecimento de vínculos sociais internos em direção à empresa elou à cadeia produtiva

Capacidade de promover e de estimular a criação de organização dos trabalhadores nas empresas sem que, no entanto, isso seja um fim em si mesmo. À luz da problemática do processo de trabalho, responder às perguntas: para que servem as comissões de fábrica ou os comitês sindicais de base nos locais de trabalho? Como devem operar no cotidiano?

Alude-se aqui a um duplo obstáculo imposto às entidades sindicais: criar e atribuir sentido estratégico às representações dos trabalhadores. Sem organização nos locais de trabalho, pouco ou nada pode ser feito para influir em seu processo. Poucas foram as entidades pesquisadas que possuíam organização no interior das empresas, e todas, segundo os depoimentos, apresentavam debilidades em seu funcionamento, sobretudo em acolher o tema do processo de trabalho como uma prerrogativa de suas ações. Vale referir que a base sobre a qual a pesquisa foi recortada - o SACC - envolve "[...] categorias profissionais que, historicamente, se colocam como referência no panorama sindical brasileiro" (Dieese, 1999:10).

Como o sindicato vai formular e controlar o resultado de uma negociação se inexistem ou são frágeis os canais de representação por que as informações sobre a empresa fluem?

Nós temos uma coisa parecida com comissão de fábrica, que é a associação dos funcionários da Embratel, que atua no local de trabalho atuando em temas internos, como as OLTs. Elas sempre estiveram em sintonia 
com o movimento sindical, mas, a partir do início dos anos 1990, com as mudanças no trabalho, nós perdemos sempre as eleições, e essa associação agora atua desvinculada totalmente do sindicato e é dirigida por gente identificada com a empresa. Isso aconteceu porque a empresa fez um trabalho ideológico junto à associação, e nós não soubemos responder a isso. [...] A empresa ocupou melhor o seu espaço interno, que deveria estar sendo disputado pelo sindicato [...]. Às vezes não sabemos contra o que lutar (dirigente sindical do Sindicato dos Trabalhadores em Telecomunicações Sinttel de Recife, trabalhador da Empresa Brasileira de Telecomunicações S.A. - Embratel; ênfases do autor).

Embora a criação de Organizações por Local de Trabalho - OLTs seja uma das bandeiras mais aclamadas pela CUT, o número de experiências nesse sentido é pequeno no Brasil. O rompimento com o imposto sindical compulsório, por exemplo, é uma realidade em poucas entidades. A permanência e a persistência do referido imposto permite que as entidades sobrevivam financeiramente, independentemente de seu grau de aproximação com as bases.

Em geral, credita-se a existência precária ou a inexistência de OLTs nas empresas exclusivamente a fatores exógenos, como a intransigência patronal e/ou a ausência de legislação que garanta o funcionamento de representações dos trabalhadores nos locais de trabalho. Embora isso seja verdadeiro, faz-se necessário considerar que parte significativa das experiências de organização dos trabalhadores nos locais de trabalho deixou de existir também por dificuldades internas dos sindicatos, sobretudo de definirem atribuições estratégicas e operações cotidianas, além das marcadamente genéricas, como "marcar posição dentro da empresa". Essas limitações endógenas têm também contribuído fortemente para o "esvaziamento" dessas experiências e para seu posterior desaparecimento.

Uma experiência que acredito ser análoga a outras tantas no Brasil ilustra o que se afirmou anteriormente. Na metade dos anos 1980, no município de Canoas, Rio Grande do Sul, em uma grande empresa do setor metalúrgico (Massey Ferguson), foi criada uma comissão de fábrica, resultado de uma greve que teve a duração de dez dias ${ }^{10}$. A planta em questão possuía, na época, cerca de 3.500 trabalhadores, e a comissão de fábrica foi eleita e integrada por cinqüenta trabalhadores, entre titulares e suplentes. A existência dessa comissão foi, no entanto, breve, cerca de um ano e seis meses. Por que a comissão de fábrica dei- 
xou de existir tão precocemente? As entrevistas realizadas com exmembros do sindicato e da comissão de fábrica nos oferecem interpretações pouco usuais no meio sindical (Cotanda, 2001:204):

Agora a gente sente, pode ver mais claramente. Havia pouco empenho nosso do sindicato, a gente tinha o temor que ela fugisse ao controle, ficasse um poder paralelo (diretor do sindicato na época; ênfase do autor).

Havia muita disputa entre os membros pra controlar a comissão de fábrica, nem o sindicato nem a comissão de fábrica sabiam direito para que ela serviria [...] nós queríamos fazer lá dentro uma luta ideológica contra o capitalismo (dirigente da CUT Estadual-RS, trabalhadora que participou das negociações que criaram a comissão de fábrica; ênfase do autor).

A situação descrita denota um vazio de atribuições para a comissão de fábrica e a falta de sintonia entre comissão e sindicato, o que se verifica em diferentes categorias e regiões do Brasil ainda hoje. As comissões são constituídas a muito custo, fragilizam-se e desaparecem. Evidentemente que contribui para tal situação a intransigência patronal, mas fica evidente também a falta de definições políticas e de atribuições por parte dos sindicatos para com as comissões de fábrica. Para que serve uma comissão de fábrica? Que atributos operacionais ela terá? Qual é seu trabalho cotidiano? "Fazer a luta ideológica contra o capitalismo"? No entanto, qual é o conteúdo prático dessa adjetivação (Cotanda, 2001)?

Permanecendo as dificuldades de definir estratégias e desenvolver capacitação que possibilite incidir sobre as contradições da produção, as comissões de fábrica estão fadadas ao enfraquecimento ou ao desaparecimento. Portanto, um imenso obstáculo endógeno à atuação sindical sobre o processo de trabalho é sua dificuldade não só em constituir uma representação dos trabalhadores, mas também em mantê-la, entre outras razões, em face do "descolamento" prático e conceitual em relação aos assuntos da produção.

\section{3) Microanalítico (a)}

Capacidade de conhecer e avaliar a composição técnica, política e cultural existente na(s) empresa(s) objeto da ação sindical.

Outro obstáculo endógeno à influência sindical encontra-se no desconhecimento e/ou na escassa valorização política da heterogeneidade da composição de classe (técnica, cultural e política) de sua base. O discurso sindical voltado para a finalidade de constituir sujeitos políticos 
nas empresas é, com exceções, dirigido aos trabalhadores homens ligados ao trabalho operatório direto. Os sindicatos, em geral, concedem pouca ou nenhuma valorização a outros segmentos de trabalhadores e às distinções de gênero. A ação sindical que busca influir sobre o processo de trabalho deveria estar alicerçada no conhecimento sistematizado e formalizado da composição técnica, política, cultural e de gênero dos trabalhadores na empresa. Esse conhecimento tem desdobramentos diretos no aprimoramento dos vínculos sociais internos. Trata-se, no entanto, de um saber que as direções sindicais relutam, não abertamente, em obter. As entidades sindicais têm dificuldades de aproximação política sobretudo com trabalhadores de maior qualificação técnica. Estes geralmente estão situados em postos-chave nas empresas, com amplo conhecimento sobre a produção e as estratégias das mesmas, sendo, portanto, fundamentais para as ações voltadas ao processo de trabalho e aos processos de inovação em particular.

\section{4) Microanalítico (b)}

Capacidade de produzir e/ou de levantar informações sobre o processo de trabalho na(s) empresa(s) e/ou na(s) cadeia(s) produtiva(s): políticas de gestão do trabalho (salários e rendimentos, rotatividade, seleção, qualificação profissional, disciplina), de organização da produção, processos de terceirização e incorporação de tecnologia na empresa.

É imperativa a construção de canais de comunicação por que possam fluir diferentes ordens de informação sobre a empresa e/ou a cadeia produtiva. O sindicato e a representação dos trabalhadores devem, como pressuposto, saber que tipo de informações estão buscando. Esses canais podem ter expressão formal, proveniente de negociação com a empresa (direito à informação antecipada sobre inovações tecnológicas e organizacionais), ou informal, por meio das organizações dos trabalhadores nos locais de trabalho.

\section{5) Microanalítico (c)}

Capacidade de, em face da variedade de informações relativas à produção de uma empresa, analisar e depreender o que é substantivo no processo de trabalho.

Estando disponíveis canais formais e/ou informais que viabilizem o fluxo de informação sobre diferentes aspectos do processo de trabalho na empresa, fazem-se necessários o tratamento e a análise dessas infor- 
mações. Não raro, são os sindicatos que obtêm informações sobre a empresa, mas têm enormes dificuldades em conferir-lhes sentido.

\section{6) Macroanalítico}

Capacidade de reconhecer e avaliar o contexto político e socioeconômico em que o sindicato, a empresa e o setor estão inseridos, bem como identificar possíveis cenários no curto, no médio e no longo prazos.

A tecnologia e a organização do trabalho (sua forma e conseqüências) não são orientadas por determinismos econômicos e tecnológicos. Entretanto, faz-se necessário compreender e dimensionar a relação que a empresa e/ou a cadeia produtiva (considerando seus produtos e mercados) guardam com as dinâmicas política, econômica e social. As estratégias sindicais com vistas à negociação do processo de trabalho devem ser direcionadas estrategicamente, levando em consideração a situação presente da empresa e do setor, bem como seus produtos e mercados.

7) Proposição (a) (em face da possibilidade de negociação formal ou informal)

Capacidade de formular propostas viáveis (considerando a correlação de forças /inserção da empresa no mercado) de aspectos estruturantes do processo de trabalho: programas de gestão do trabalho e de inovação tecnológica.

Significa que a entidade deve, diante de um processo de negociação, ser capaz de formular propostas (o que colocar no lugar do que é criticado) considerando a inserção da empresa (contexto macroeconômico e mercado) e a expressão da correlação de forças. Propostas inviáveis, como "marcar posição", que desconsiderem os referidos contextos, dificultam a contratação da influência. Ser propositivo também significa "encarar" a negociação. Não é incomum que as entidades sindicais tenham receio do processo negocial envolvendo temas da produção, sobretudo quanto a "não ser enrolado" pela empresa ou a legitimar determinada mudança tecnológica ou organizacional por meio da assinatura de um acordo. Tal receio só será superado com a prática, rompendo, portanto, com a perplexidade imobilizadora.

8) Proposição (b) (nível das micromudanças) 
Capacidade de influir sobre propostas e ações cotidianas de mudanças de processos no "chão de fábrica", oriundas dos próprios trabalhadores diretos ou viabilizadas a partir de sua atuação.

A influência sindical nem sempre se expressa contratualmente. Pequenas ou grandes alterações no processo de trabalho podem ser negociadas informalmente, por exemplo, entre trabalhadores de uma seção da empresa e a gerência. O sindicato deve ser capaz de influir sobre esses processos informais.

\section{9) Monitoramento}

Capacidade de monitorar a implementação dos acordos formais e/ou informais.

É evidente a distância existente entre a contratação de uma reivindicação e sua implementação prática. Uma vez realizados acordos (formais ou informais), o sindicato e a representação dos trabalhadores na empresa devem ser capazes de dispor de meios para acompanhar sua implementação.

\section{0) Antecipação}

Capacidade de "perceber", antecipadamente, possíveis ondas de inovação de produtos e processos (tecnologia e organização) e de avaliar seus efeitos.

Sobretudo as empresas expostas à competição estão em constante processo de mudanças (produtos, processos e mercados). O sindicato e a representação dos trabalhadores na empresa devem desenvolver capacitação e vínculos sociais externos que lhes permitam prever movimentos de inovação.

A fala do dirigente sindical, transcrita a seguir, mostra que a ação sindical que ocorre após a implementação das mudanças organizacionais se reveste das maiores dificuldades: "[...] a implantação deste progra$\mathrm{ma}^{11}$ foi feita de forma muito sutil, envolvente, sem estardalhaço [...] o sindicato demorou demais para entender e agir. Agora, o terreno a percorrer é muito maior" (dirigente sindical do Sinttel de Recife, trabalhador da Embratel). 


\section{1) Mobilização}

Capacidade de desenvolver estratégias de pressão que acompanhem o processo de negociação.

Seguramente, a influência sindical nos assuntos da produção não será obtida exclusivamente com base na pertinência das propostas. $\mathrm{O}$ desequilíbrio de forças entre capital e trabalho impõe que estratégias de pressão, orientadas pelo sindicato, acompanhem os processos de negociação.

\section{2) Inserção institucional (setorial e nacional)}

Capacidade de desenvolver atuação política em âmbito setorial e institucional de sorte que se estabeleçam os nexos entre a dimensão micro do processo de trabalho (espaço da empresa) e as determinações meso e macrorregulatórias.

Embora o processo de trabalho tenha existência concreta na empresa, as escolhas envolvendo tecnologia e organização do trabalho são também influenciadas por decisões em outros âmbitos, por exemplo, nas câmaras setoriais regionais, nos programas de qualidade e produtividade, nos fóruns de política industrial, entre outros. Cabe aos sindicatos mais do que simplesmente ocupar esses espaços, atuar proativamente, diagnosticando, reivindicando e lutando para que esses espaços estejam articulados a estratégias nacionais de política industrial e de desenvolvimento. A atuação sindical local (na fábrica) e institucional incide uma sobre a outra, fortalecendo-se mutuamente.

\section{3) Constituição e/ou ampliação de vínculos sociais externos}

Capacidade de desenvolver e/ou ampliar vínculos sociais com atores significativos, externos ao sindicato, capazes de apoiar a consecução de diferentes estratégias sindicais relativas ao processo de trabalho.

A complexidade das questões relacionadas à produção impõe ao sindicato o desenvolvimento de vínculos sociais com diferentes entidades da sociedade civil (universidades, ONGs, partidos políticos), bem como com outras organizações sindicais dentro e fora do Brasil. A pauta sindical sugerida pela temática do processo de trabalho é complexa, demandando amplo esforço de formulação. Os vínculos sociais podem produzir importantes experiências de assessoria e de capacitação, além de aproximação com outras entidades sindicais, sobretudo do 
mesmo ramo, no Brasil e no exterior, possibilitando, além da troca de experiências, o entendimento facilitado de dinâmicas produtivas globais.

\section{4) Inovação e protagonismo}

Capacidade de promover pesquisas e/ou de associar-se a centros de pesquisa visando gerar conhecimento (desenvolvimento tecnológico) relativo a produtos e a processos (tecnologia e gestão do trabalho).

As ações sindicais envolvendo o processo de trabalho ocorrem, em geral, defensivamente, depois que as mudanças foram implementadas na empresa. A entidade deveria ser capaz de, juntamente com estruturas de apoio, dar início a um salto cultural: projetar de forma alternativa novos conteúdos para tecnologia, produtos e processos (atuação ofensiva). Ações desse porte exigem alto grau de desenvolvimento dos demais atributos mencionados anteriormente, bem como atuações sindicais coordenadas.

\section{CONSIDERAÇÕES FINAIS}

Ao longo deste estudo, tratei dos sindicatos filiados à CUT. Com base nas pesquisas, busquei problematizar a relação dessas entidades sindicais com os processos de inovação, possibilitando desenvolver um conjunto de argumentos, dentre os quais se destacam:

- a análise das experiências de contratação de cláusulas que versam, direta ou indiretamente, sobre os processos de inovação evidencia que o número de cláusulas contratadas demonstra que o tema em questão esteve presente na agenda dos sindicatos filiados à CUT, sobretudo nas categorias tidas como referência no panorama sindical brasileiro. Em larga medida, esse fenômeno se deve ao trabalho de sensibilização realizado pela CUT, bem como às experiências de negociação levadas a cabo por alguns sindicatos, sendo o exemplo mais expressivo o Sindicato dos Metalúrgicos do $\mathrm{ABC}$;

- o exame do conteúdo das cláusulas negociadas mostrou que este apresenta características predominantemente defensivas, genéricas e contingentes;

- não obstante o número de acordos tenha aumentado se comparado à década de $1980^{12}$, seu desdobramento prático não foi alentador, pois as entidades investigadas não obtiveram o efeito prático para o qual as 
cláusulas contratadas se destinavam. Sendo assim, a influência sindical se mostrou pouco ou nada efetiva;

- a despeito desse resultado, a existência dos contratos significa um ponto de partida importante para os sindicatos. Nesse sentido, a realidade dos acordos poderia e pode ser outra, caso haja maior desenvolvimento de capacitação das entidades no enfrentamento conceitual e prático do tema;

- a superação dos obstáculos - sobretudo os endógenos - à influência sindical sobre os assuntos da produção supõe o desenvolvimento de capacitação em diferentes dimensões. A análise procedida possibilitou a identificação de quatorze expressões dessa capacitação que estiveram ausentes ou parcialmente presentes nas entidades sindicais examinadas;

- de forma geral, o desenvolvimento de capacitação visando à influência sindical nos assuntos da produção implicaria mudanças internas nas entidades, bem como na ampliação de seus vínculos sociais ${ }^{13}$ externos (redes de apoio técnico e político) e internos (junto à categoria). Evidentemente que, ao referir os quatorze atributos, minha intenção não foi propor um conhecimento normativo, uma "receita" a ser aplicada pelos sindicatos, tampouco imaginei ter esgotado os caminhos pelos quais essas entidades poderiam capacitar-se para atuar de forma mais eficiente nos assuntos da produção. Trata-se de um esforço de análise para melhor compreender e demonstrar os constrangimentos que se interpõem entre os sindicatos e o caminho da influência sobre o processo de trabalho.

O fato de ter sido concedida ênfase à análise dos obstáculos aqui denominados endógenos, em detrimento de uma análise mais exaustiva dos obstáculos exógenos, não significa que tenha sido feita uma escolha influenciada pela relevância de um sobre o outro na explicação dos fenômenos envolvendo a relação entre sindicatos e inovação tecnológica e organizacional. O malogro em influenciar os rumos da inovação por parte dos sindicatos deveu-se tanto aos fatores exógenos quanto aos fatores aqui chamados de endógenos. Ao enfatizar os últimos, busquei analisar um ambiente empírico que é menos problematizado na literatura sobre sindicalismo. Essa escolha foi feita de modo consciente, reconhecendo que os obstáculos possuem implicações mútuas, e a separação operada serve apenas a propósitos analíticos. 
Finalmente, gostaria de afirmar que o processo de trabalho foi concebido como um campo que dialeticamente encerra a produção de conflito e de consenso e que as inovações que o modelam tendem a desempenhar um papel na produção e na reprodução das relações sociais, indo além, portanto, de sua dimensão técnica. A importância da atuação sindical sobre os processos de inovação decorre justamente da dimensão política do processo de trabalho. O eventual afastamento desse campo de conflito por parte das entidades é fenômeno socialmente produzido.

Os assuntos atinentes ao mundo da produção e as decisões sobre seus rumos são, em geral, concebidos como de natureza privada, sendo ainda frágeis e limitadas as manifestações de controle público e/ou de negociações envolvendo sindicatos e empresas.

O sindicalismo, conforme argumentado, não é portador de um "destino objetivo" (Laclau e Mouffe, 1987); e, por essa razão, faz-se necessário que ele afirme, no presente, suas conviçções e seus projetos referentes à forma e ao conteúdo do trabalho. A ação sindical que busca influir nos assuntos da produção é, no entanto, tolhida por obstáculos que se originam da referida assimetria de poder entre capital e trabalho, bem como das próprias escolhas e estratégias sindicais. Nesse sentido, os obstáculos à influência sindical sobre a tecnologia e a organização do trabalho podem estar situados mais ou menos próximos de sua governabilidade.

Concomitantemente à fragilização do trabalho e dos sindicatos nos anos 1990, foi observado um interesse maior por parte destes em atuar no âmbito da produção, ainda que essa atuação venha sendo feita de forma predominantemente reativa. Não há incompatibilidade entre as lutas sindicais de cunho salarial e as dirigidas ao processo de trabalho. A atuação sindical nesse campo de conflito, ao contrário de produzir um confinamento no plano micro, possibilitaria o estabelecimento de nexos entre os planos local e global das empresas, e nisso residiria um expressivo potencial de conscientização política. Para tanto, é necessário que os sindicatos vão além da mera reação aos efeitos negativos dos processos de inovação e atuem de forma proativa sobre o processo de trabalho, o que, no juízo deste estudo, contribuiria para a revitalização do movimento sindical em novas bases.

(Recebido para publicação em maio de 2007)

(Versão definitiva em agosto de 2008) 


\section{NOTAS}

1. ACUT, fundada em 28 de agosto de 1983, possui atualmente 3.428 entidades filiadas. Trata-se de um número elevado de entidades filiadas, que, se de um lado expressa o grau de penetração social da Central, de outro evidencia a nefasta pulverização da representação sindical. A CUT possui 21.915.014 trabalhadores em sua base, sendo que, desses, 7.413 .913 são associados a suas entidades. Está organizada em 27 estados e no Distrito Federal. (Dados fornecidos pela CUT em janeiro/2008.)

2. A afirmação de que a CUT possui formalmente o propósito de influir sobre os processos de inovação está embasada em pesquisa documental realizada nas resoluções dos oito congressos da CUT Nacional no período de 1984 a 2003, conforme Cotanda (2001) e pesquisa de atualização realizada posteriormente.

3. A lista das entidades cujos dirigentes foram entrevistados consta do Anexo.

4. Análises que enfatizam essa experiência podem ser encontradas em Arbix (1995); Bresciani (2001); Cotanda (2001); Paulino e Marcolino (1999); entre outros.

5. Os grifos que constam das citações literais são meus.

6. Os dirigentes sindicais das entidades sindicais que estão localizadas nos estados de Goiás, Minas Gerais, Paraná, Rio Grande do Norte, Pernambuco, Ceará e Bahia foram consultados por intermédio de contato telefônico; os demais foram entrevistados in loco.

7. Paradoxalmente, a importância do processo de trabalho para o entendimento das relações de poder e dominação nas relações de trabalho está sobejamente demonstrada na narrativa de Marx. Vale lembrar também as propostas da "oposição de esquerda", liderada por Alexandra Kollontai, apresentadas em 1921 no XX Congresso do Partido Bolchevique, visando conferir maior autonomia aos trabalhadores nos assuntos relativos à produção. As propostas foram rechaçadas por Trótski e, posteriormente, por Stálin.

8. Os obstáculos exógenos foram considerados de forma pormenorizada em Cotanda (2001).

9. Agradeço a Luís Paulo Bresciani os comentários e sugestões relativos ao desenvolvimento desse tópico.

10. As informações sobre a experiência vivida pelos trabalhadores da Massey Ferguson e o Sindicato dos Trabalhadores Metalúrgicos de Canoas foram obtidas por ocasião da realização das pesquisas para minha tese de doutorado. Informações adicionais sobre essa experiência podem ser obtidas em Cotanda (2001); especialmente nas páginas 11 e 203.

11. O entrevistado refere-se ao "Programa de Qualidade" implementado na Embratel, com o apoio da Fundação Christiano Ottoni, em 1990.

12. Conforme Cotanda (2001).

13. Devo a Scott Martin a idéia de vínculos sociais utilizada neste artigo. 


\section{REFERÊNCIAS BIBLIOGRÁFICAS}

ARBIX, Glauco. (1995), Uma Aposta no Futuro: Os Três Primeiros Anos da Câmara Setorial da Indústria Automobilística e a Emergência do Meso-Corporativismo no Brasil. Tese de doutorado em Sociologia, FFLCH/USP, São Paulo.

BRESCIANI, Luís Paulo. (1994), Da Resistência à Contratação: Tecnologia, Trabalho e Ação Sindical no Brasil. Brasília, Sesi-DN.

. (2001), O Contrato da Mudança: A Inovação e os Papéis dos Trabalhadores na Indústria Brasileira de Caminhões. Tese de doutorado em Política Científica e Tecnológica, Instituto de Geociências, Unicamp, Campinas.

CARDOSO, Adalberto Moreira. (1999), Sindicatos, Trabalhadores e a Coqueluche Neoliberal: A Era Vargas Acabou? Rio de Janeiro, Editora FGV.

COTANDA, Fernando. (2001), Sindicalismo e Inovação Tecno-Organizacional: A Experiência da Central Única dos Trabalhadores. Tese de doutorado em Sociologia, UFRGS, Porto Alegre.

DIEESE - Departamento Intersindical de Estatística e Estudos Socioeconômicos. (1999), Acordos e Convenções Coletivas: Cláusulas Selecionadas. São Paulo, Dieese. (Pesquisa Dieese, no 9, edição especial.)

LACLAU, Ernesto e MOUFFE, Chantal. (1987), Hegemonía e Estrategia Socialista: Hacia una Radicalización de la Democracia. Madrid, Siglo XXI.

PAULINO, Ana Yara e MARCOLINO, Adriana M. (1999), “A Busca de Novos Espaços de Negociações Sindicais frente à Reestruturação Produtiva: O Caso da Mercedes-Benz do Brasil de São Bernardo do Campo", in Dieese (org.), Emprego e Desenvolvimento Tecnológico: Artigos dos Pesquisadores. São Paulo, Dieese/Cesit.

SALERNO, Mario Sergio. (1999), Projeto de Organizações Integradas e Flexíveis: Processos, Grupos e Gestão Democrática via Espaços de Comunicação-Negociação. São Paulo, Atlas. 


\section{ANEXO \\ Entidades Sindicais (diretores entrevistados)}

Cabe referir que os diretores sindicais cujas entidades se situam nos estados de Pernambuco, Ceará, Rio Grande do Norte, Bahia, Paraná e Goiás foram entrevistados por meio de ligação telefônica; os demais foram entrevistados in loco*.

- Confederação Nacional dos Bancários

- Federação dos Bancários do Rio Grande do Sul (RS)

- Federação dos Trabalhadores nas Indústrias Gráficas de São Paulo (SP)

- Federação dos Trabalhadores nas Indústrias do Papel e Papelão(SP)

- Sindicato dos Aeroviários do Rio Grande do Sul (RS)

- Sindicato dos Bancários de Porto Alegre (RS)

- Sindicato dos Jornalistas Profissionais de Belo Horizonte (MG)

- Sindicato dos Jornalistas Profissionais de Fortaleza (CE)

- Sindicato dos Jornalistas Profissionais de Pernambuco (PE)

- Sindicato dos Jornalistas Profissionais de Porto Alegre (RS)

- Sindicato dos Jornalistas Profissionais do Rio Grande do Norte (RN)

- Sindicato dos Jornalistas Profissionais de São Paulo (SP)

- Sindicato dos Oficiais Alfaiates de São Paulo (SP)

- Sindicato dos Oficiais Marceneiros de São Paulo (SP)

- Sindicato dos Petroquímicos da Bahia (BA)

- Sindicato dos Químicos do Rio de Janeiro (RJ)

- Sindicato dos Químicos de São Paulo (SP)

- Sindicato dos Telefônicos de Minas Gerais (MG)

- Sindicato dos Telefônicos de Pernambuco (PE)

- Sindicato dos Telefônicos do Rio Grande do Sul (RS)

- Sindicato dos Trabalhadores da Construção Civil de Curitiba (PR)

\footnotetext{
* Ainda como esclarecimento, vale destacar que os sindicatos dos Oficiais Alfaiates de São Paulo, dos Trabalhadores em Transporte Rodoviário de Goiás, dos Trabalhadores da Indústria do Fumo do Paraná e a Federação dos Trabalhadores nas Indústrias do Papel e Papelão de São Paulo, que constam desta listagem, não eram filiados a nenhuma das centrais sindicais na época dos acordos examinados. A Federação dos Trabalhadores nas Indústrias Gráficas de São Paulo estava filiada à Força Sindical.
} 
- Sindicato dos Trabalhadores da Construção Civil de Fortaleza (CE)

- Sindicato dos Trabalhadores da Indústria do Fumo do Paraná (PR)

- Sindicato dos Trabalhadores das Indústrias de Artefatos e Borracha de Pernambuco (PE)

- Sindicato dos Trabalhadores nas Indústrias Metal Mecânica e Material Elétrico de Curitiba (PR)

- Sindicato dos Trabalhadores das Indústrias Metalúrgicas do Rio de Janeiro (RJ)

- Sindicato dos Trabalhadores nas Indústrias Químicas e Petroquímicas (Sindipolo/RS)

- Sindicato dos Trabalhadores das Indústrias do Trigo e Milho de Salvador (BA)

- Sindicato dos Trabalhadores em Processamento de Dados do Rio Grande do Sul (RS)

- Sindicato dos Trabalhadores Metalúrgicos do ABC de São Paulo (SP)

- Sindicato dos Trabalhadores Metalúrgicos da Bahia (BA)

- Sindicato dos Trabalhadores Metalúrgicos de Canoas (RS)

- Sindicato dos Trabalhadores Metalúrgicos de Porto Alegre (RS)

- Sindicato dos Trabalhadores Metalúrgicos de São José (RS)

- Sindicato dos Trabalhadores em Transporte Rodoviário de Goiás (GO) 


\section{ABSTRACT \\ Brazilian Trade Unions' Stance Towards Technological and Organizational Innovations}

The article analyzes trade union action that seeks to influence processes of technological and organizational innovation in companies in Brazil. The System for Monitoring Collective Bargaining, under the Inter-Union Department of Statistics and Economic Studies (SACC-Dieese), was used to analyze collective bargaining clauses (1990-2005) that deal with innovative processes. Interviews were held with leaders of unions belonging to the SACC-Dieese, seeking to understand what actually occurred following formal agreement to the clauses. We observed that the agreed-upon terms were not enforced in practice, revealing that the trade unions' influence in innovative processes was merely "apparent". The article seeks to demonstrate that the limited success of Brazilian trade unions in affecting technological and organizational innovations has been due not only to external constraints, but also to the unions' own limitations in formulating and interacting with technical and organizational changes.

Key words: work; innovation; unions

\section{RÉSUMÉ}

Les Syndicats Brésiliens face aux Innovations Technologiques et Organisationnelles

Dans cet article, on étudie l'action syndicale qui cherche à influencer les processus d'innovation technologique et organisationnelle dans les entreprises. À partir du Système d'Accompagnement des Contrats Collectifs (SACC-Dieese), on a examiné le contenu des clauses et des accords et/ou des conventions collectives qui incident sur les processus d'innovation concernant la période 1990-2005. On a eu des entretiens avec des dirigeants des groupes qui forment le SACC-Dieese afin de savoir les résultats de l'application de ces contrats: ils semblent avoir été peu tangibles puisque l'influence syndicale n'a été qu'"illusoire". On voit que le succès relatif des syndicats dans leur influence sur les innovations technologiques et organisationnelles vient non seulement des contraintes extérieures mais de leurs propres limites d'expression et d'interaction face aux changements techno-organisationnels.

Mots-clé: travail; innovation; syndicats 